\title{
The Coaching Behaviours and Philosophy of High Performance Secondary School Basketball Coaches 出色表現的中學籃球教練行為及哲學理念
}

\author{
Alberto CRUZ \\ Department of Health \& Physical Education, \\ The Hong Kong Institute of Education, HONG KONG \\ 高達倫 \\ 香港教育學院健康與體育學系
}

\begin{abstract}
The purpose of the study was to examine the coaching behaviours and philosophy of four high performance secondary school basketball coaches during their in-season practice sessions. A mixed-method approach was used to identify the coaching behaviours used by the four coaches in the practice environment and to generate an insight into the rationales that underpinned their use. They were videotaped and observed coaching four practice sessions with their own teams. The videotaped sessions were coded using the Arizona State University Observation Instrument (ASUOI) (Lacy \& Darst, 1984). Data generated by the ASUOI provided information of the percentages of coaching behavioral categories of the coaches. The four coaches were interviewed after their practice sessions. Qualitative data were collected through field observations and interviews. Constant comparison and analytic induction were used to organize and categorize the data. Data analyzing attempted to provide explanations and rationales for their coaching behaviours and philosophy in the practice sessions. Findings of the study helped to provide a more holistic understanding of the coaching behaviours and philosophy of high performance basketball coaches. This information is invaluable and significant in the training and advancement of both apprentice and veteran coach in basketball as well as other sports areas.
\end{abstract}

Keywords: coaching behaviours, coaching philosophy, basketball coaches

\section{摘 要}

本研究目的是探究四位出色表現中學籃球教練在賽季訓練時的教練行為及哲學理念。研究方法是採用混合模式去識別教練行 為及其背後理念。教練被錄影及觀察四節球隊訓練課。訓練課利用ASUOI觀察系統分析教練行為及提供行為百分比資料。四位教 練於訓練課後接受訪談。以持續比較法分析歸納訪談及觀察數據説明教練行為及哲學理念原因。研究結果協助全面理解教練行為 及哲學理念。此等資料對於培訓新手及經驗籃球教練及其他運動教練场為重要。

關鍵詞： 教練行為、教練哲學理念、籃球教練 


\section{Introduction}

Sport coaching has rapidly developed and recognized as a profession (Duffy et al., 2011) in recent years, the demand of understanding the coaching effectiveness and competence is increasing. Sports educators therefore would like to understand what the coaches are doing during the practice sessions in order to improve the coaching performance. The analysis of coaching behaviours in practice indeed helps to recognize how coach facilitates learning for the athletes (More \& Franks, 1996). In the last two decades, observing the coaching behaviours of sport coaches and understanding how they facilitate the learning process has become important research agenda in sport coaching.

The importance of using of direct observation in coaching practice has been recognized (Erickson, 2009). With the constant research production on coaching behaviours in past decades, it seems that direct observation of coaches is an appropriate method for studying coaches' behaviour in training and competition (Gallimore \& Tharpe, 2004; Trudel, Coté, \& Donohue, 1993). Indeed, systematic observation instruments have been developed and are employed in studying coaching behaviour (Cushion \& Jones, 2001). The Arizona State University Observational Instrument (Lacy \& Darst, 1984) and the Coaching Behavioral Assessment System (Smith, Smoll, \& Hunt, 1977) were identified as the two most commonly used coaching observation instruments in the study of sport coaches (Erickson, 2009). A number of studies have used systematic observation techniques to study coaches' behaviours of all levels during training and competitions in a wide range of sports (e.g. Becker \& Wrisberg, 2008; Cushion \& Jones, 2001; Mesquita, Sobrinho, Rosado, Pereira, \& Milistetd, 2008; Potrac, Jones \& Armour, 2002; Van der Mars, Darst, \& Sariscany, 1991; Zeng, Leung, Bian., \& Liu, 2009). These studies tended to produce consistent results with instruction being the most frequent used behaviour in various levels and sport contexts (Gallimore \& Tharpe, 2004; Kahan, 1999). In a review of literature on the studies of coaching effectiveness which used systematic observation to examine coach behaviours in training, Douge and Hastie (1993) identified five characteristics of effective coaches: a) frequently provide feedback and incorporate prompts and hustles, b) provide high levels of correction and reinstruction, c) use questioning and clarifying, d) involve in giving instruction, and e) manage the training environment (pp. 15-16).
To understand better the coaching effectiveness, researchers chose to study the profiles, knowledge and practices of successful and high performance coaches (Becker \& Wrisberg, 2008; Bloom \& Salmela, 2000; Coté \& Sedgwick, 2003; Hardin, 2000; Hardin \& Bennett, 2002; Potrac, Jones, \& Armour, 2002; Wang \& Straub, 2012). Studies show some common elements and characteristics shared by these successful high performance coaches. These coaches usually spend more time in training and instruction than any other type of coaching behaviour. Their presentation during coaching is mostly positive and constructive and they tend cultivate a positive learning environment. The successful coaches give greater amount of overall feedback in practice than do the less effective counterparts. They largely use praise to enhance selfefficacy and confidence level of learners. They are serious about their coaching in terms of planning and managing. They have detailed planning and practice procedures. Their established routines help them to accomplish training tasks during coaching. They also possess ability in observe, analyse, synthesize and modify their coaching to fit the situation and the needs of learners. They are effective communicators and highly skilled problem solvers with extensive knowledge in their filed. They display a strong work ethic and have an ongoing quest for personal growth and knowledge and are also regarded as good teachers as well. The information generated by these studies would help the practice and coach's development.

Coté and his colleagues have postulated a coaching model to represent the important components related to the coaching process and development of elite athletes. This theoretical model attempts to explain which factors were most important for coaches. They pointed out that central to the coaching process are coaches' behaviours in training, competition, and organizational settings. Affecting these three variables are the coach's personal characteristics, athletes' personal characteristics and level of development, and contextual factors (Coté, 1998; Cote \& Salmela, 1996; Coté, Salmela, Trudel, Baria, \& Russell, 1995). The model is noteworthy as it provides a comprehensive framework to explain the process of coaching and guide the actual practice of coaches in applied settings. Besides, the model has been found to be applicable to the environmental of team sports and combat sports and represented the knowledge and work of expert coaches in various team sports (Bloom \& Salmela, 2000; Moraes \& Salmela, 2001). As the major purpose of this study is to examine the coaching practice and 
philosophical beliefs of high performance secondary school basketball coaches, therefore, the Coaching Model (Coté, 1998; Coté, Salmela, Trudel, Baria, \& Russell, 1995) is used as the conceptual framework for the study.

In Hong Kong, basketball is one of the most popular sports activities (Sports Development Board, 2003). Hong Kong Basketball Association has conducted basketball coaches training courses regularly. The main purpose of these training courses is to improve the quality and competence of basketball coaches. In the review of Hong Kong sports literature by the investigator, there is limited study conducted relate to basketball coaching. The present study attempts to provide the first description of coaching behaviours and coaching philosophy of high performance secondary school basketball coaches. It is hoped that the results generated may help to provide information and rationales of the coaching practice of high performance basketball coaches which in turn enhance coach's development in youth basketball training. Moreover, studying the philosophy and practices of high performance coaches is important to coach education as the study will generate information on different areas of coaching and help to improve the coaching effectiveness. This study also represents a beginning effort to develop an understanding of coaching philosophy of high performance secondary school basketball coaches and how they coach their athletes in in-season practice sessions. This information will be invaluable to novice basketball coaches because this knowledge may help them to plan and coach their daily practice sessions and eventually accelerate the process of getting become proficient basketball coaches.

In order to achieve the aforementioned objectives, two research questions are set to guide the inquiry of the study: 1) What are the coaching behaviour patterns of the four high performance basketball coaches during their in-season practice sessions? and 2) What are the common coaching philosophies of the four high performance basketball coaches?

\section{Methods}

For the purposes of the study, the investigator employed a mixed method approach to address the above research questions. The quantitative approach mainly deals with the data captured by the observation instrument, the Arizona State University Observation Instrument (ASUOI) (Lacy \& Darst, 1984). Since sport coaching is a complex process (Coté, Salmela, \& Russell, 1995), the qualitative methodologies are also used as alternative means to provide further information on the coaching process and patterns of coaching in the natural setting. The qualitative data collection techniques were post-coaching interviews and the taking of field notes during field observations. It was anticipated that a combination of methods would facilitate a more holistic view of the coaches and the multifaceted processes behind instructional behaviour (Potrac, Brewer, Jones, Armour, \& Hoff, 2000; Potrac, Jones, \& Armour, 2002). Moreover, such triangulation of research methodologies has been recommended by other researchers (Denzin, 1989; Patton, 1990) and assists to understand the observed behaviours from the participant's perspective. This study design has sought to provide a comprehensive view of the coaching practice of the basketball coaches.

\section{Participants}

The participants for this study were three males and one female high performance basketball coaches. Due to the multiple ways in which people in conceptualize the notion of high performance, the identification of high performance coaches posed some difficulties. However, previous studies on expert coaches gave some guidelines for participant selection (Claxton, 1988; Jones, Housner, and Kornspan, 1995; Lacy \& Darst, 1985). The criteria employed to select high performance coaches include: a) at least five years coaching experience; b) good winning record or help coaching team gaining awards in basketball competition; c) recognition for outstanding coaching (e.g., recognized by the Hong Kong Basketball Association or the Hong Kong Schools Sports Federation), and d) accessibility to the investigator. All four coaches obtained university degree in physical education and were accredited qualified coaches for the Hong Kong Basketball Association. They are secondary physical education teachers and coaching basketball teams from under 13 until under 18 in their secondary schools. The participants averaged 32 years of age and 11.3 years as coaches in secondary school basketball. The sampling was intentional and fulfilling all the criteria as high performance set by the investigator. The participants were purposely invited and they agreed to take part in the study. The informed consent was obtained from the coaches prior to commencement of the study. 


\section{Instrumentation}

Systematic observation. The instrument employed for this study was the Arizona State University Observation Instrument (ASUOI) (Lacy \& Darst, 1984). The instrument was specially designed to examine coaching behaviours of coaches in the practice environment, and is based on the 10-category system originally devised by Tharp and Gallimore (1976) for the systematic observation of coaching behaviour within the teaching/coaching setting. The ASUOI has 14 behavioural categories (see Appendix 1 for full list of categories and definitions), seven of which are directly related to the instructional process (i.e., pre-instruction, concurrent instruction, post-instruction, questioning, physical assistance, positive modeling, and negative modeling). The behavioral categories of the ASUOI are based on conceptual rationale that satisfy the criteria for both content and face validity (Lacy \& Darst, 1989). In addition, as a rational basis exists for the selection of the behaviour categories and these behaviours are representative of coaching behaviour as supported by previous research (e.g. Claxton, 1988; Claxton \& Lacy, 1986; Cushion \& Jones, 2001; Lacy \& Goldston, 1990; Miller, 1992).

In order to establish the accuracy and consistency of the systematic observation procedures, the intra-observer reliability of both instrument and the researcher was established (Thomas, Nelson, \& Silverman, 2011). Intraobserver reliability refers to the extent to which there is agreement between different records of the same event, made by the same observer, but at different times (Brewer \& Jones, 2002). An intra-observer reliability test was carried out by analyzing a videotaped coaching session using time-sampled event recording (Claxton, 1988). For allowing memory lapse, the investigator analyzed the same coaching session again after two weeks. The level of intra-observer reliability was then determined by calculating the percentage of agreements between observations 1 and 2 for the frequency (the number of times behaviours were recorded) of each behaviour classification. Here, the agreement percentages reached $95.2 \%$ and exceeded the accepted level of 85 per cent recommended by Van der Mars (1989), meaning a strong consistency.

Non-participant observation. The investigator made field notes recording during coach observations in addition to systematic observation. The main purpose is to have a better understanding of the coaching practice. Marshall and Rossman (1995) described the observation as "the systematic noting and recording of events, behaviours and artifacts in the social setting chosen for study" (p. 79). The coaching behaviours observed during the coaching session is always purposely and indicative of the participants' coaching philosophy and beliefs. During the observation of the participants, field notes related to the coaching activities were taken in the form of a field journal. Bogdan and Biklen (1992) define field notes as the written account of what the researcher sees, hears, experiences, and thinks in the course of collecting and reflecting on data. After the field observations, the investigator reviewed, commented, and elaborated on the notes to make sense of the data. The investigator then read through the field notes to look for the regular occurrences across coaches and to generate initial fidelity themes.

Interviews. In addition to coaching observations, each coach was interviewed. Since systematic observation cannot provide an insight into why coaches do what they do (Potrac \& Jones, 1999; Potrac, Jones, \& Armour, 2002), interviews were used as supplement to help the interpretation and understanding of coaches' actions and cognitions in practice (Martens, 1987; Potrac, Brewer, Jones, Armour, \& Hoff, 2000). In the present study, all the interviews were conducted using a semi-structured approach with open-ended questions. The questions were used to elicit information from the participants about their a) conceptions about coaching basketball, b) perception of the coach's role, c) their preparation in practice sessions, d) their workplace, and e) comments on their practice of coaching.

\section{Procedures}

The coaches were videotaped four in-season practice sessions of their basketball teams training. Each observation consists of three 15 -minute periods with a 5-minute break between two segments. Total amount of time coded from each practice session is 45 minutes, giving a total of 180 minutes of each coach.

For the purpose of this study, each practice session was coded using the Arizona State University Observation Instrument (ASUOI) (Lacy \& Darst, 1984). A trained observer stood near the technical area to record the participants' behaviours and conducted all observations live. The videotaping of each trainings session started 
when the athletes were assembled in order to start the training and ended when athletes were then released by coach. During all of the recorded sessions, coaches were wearing a wireless microphone to ensure to capture all of their verbal communications. Data were recorded using time sampled event recording (Rushall, 1977). The data were analysed in terms of specific events (event recording) and time intervals spent in each behaviour category (interval recording). In order to establish the accuracy and consistency of the systematic observation procedures, the intra-observer reliability is checked by using the method recommended by Van der Mars (1989) as aforementioned. In addition, field notes were kept by the investigator, as a supplement to help explain and expand upon the data (Segrave \& Ciancio, 1990).

Post-coaching interviews were also conducted within one week after the videotaping of the last practice sessions. The investigator made sure the interviewee felt welcomed and at ease before any data collection began (Lincoln \& Guba, 1985). This was done by building rapport with each coach before the interview session by explaining the confidentiality of the analysis and by emphasizing that there was no right or wrong answers to the questions. To ensure that nothing was overlooked, participants were periodically asked if they had anything else to share about their experiences. Interviews ranged from 30 to 90 minutes in length. Participants were given a pseudonym to preserve their anonymity throughout the process. Each interview was audio-taped and transcribed for further analysis.

\section{Data Analysis}

Systematic observation data generated by the ASUOI coding procedure were computed into a total number of behaviours and a percentage was achieved from the total behaviours observed. Percentages and rate per minute (RPM) for each category were calculated and totaled. Percentages were calculated by dividing each independent behavior category by the total number of independent behaviours. The RPM for each behaviour was calculated by dividing the total of each category by the total number of minutes of observation. These descriptive data allow comparison with the results of other studies in this area.
Qualitative data for this study consist of interview records and field notes of practice observations. All interviews and field notes of practice observations were fully transcribed. The investigator tried his best to maintain the originality of the participant's meaning without adding or altering the contents of the interviews. After the data were transcribed and re-organized, the transcript was sent to the participants for their verification of the accuracy of the interview content. The participants affirmed that the investigator' written transcript accurately reflected interview content and there were no errors in the written transcript. The data were then analyzed inductively (Manning, 1991) by using a constant comparison method (Denzin \& Lincoln, 1994), a process of searching themes and commonalities from data. Through careful reading, inspection and reviews, themes were identified and clustered within the data. Emerged categories were refined and were separated according to each theme. The investigator sought for the prominent patterns within the study as a whole. Establishing trustworthiness assists the research process is properly conducted and findings are worthy and credible (Lincoln \& Guba, 1985). Several measures were taken to ensure the trustworthiness of the data: triangulation, peer debriefing and member checks. First, the investigator used multiple data sources to crosscheck the accuracy of data gathered from one source to another (LeCompte \& Preissle, 1993). The multiple data sources helped establishing the credibility of the data (Denzin, 1989). Second, peer debriefing (Lincoln \& Guba, 1985) was conducted with a colleague who has extensive qualitative research experience in physical education. He was invited to examine the coding procedures and verified the final categories and preliminary analysis. Third, the member checks procedure was used (Merriam, 1998). The investigator performed member checks with all participants to verify the accuracy of our transcriptions and interpretation of the interview transcript and field notes. On the whole, all these processes help to ensure the validity of the findings.

With regard to ethical considerations, the investigation also complies with the institute's ethical policies on the use of human subjects. All information was treated with the strictest confidentiality and the identity of participants was protected. Pseudonyms have therefore been used in the reporting of the findings. 


\section{Results}

The purpose of the present study was to examine the coaching behaviours and philosophy of four high performance secondary school basketball coaches during their in-season coaching practice. Data generated help us understand their coaching philosophical beliefs and practice in coaching.

\section{Coaching behaviours}

Quantitative data generated by the systematic observation provide some information of the coaching behaviours of the participants in the study and they are shown in Table 1. The number of behaviours observed, percentage, and the RPM for each defined category of the ASUOI for the 4 participants during the in-season phase are presented. As illustrated in Table 1, a total of 3044 behaviours were recorded from the coaches under study. The four most widely used behaviours during the inseason for all participants were concurrent instruction (40.2\%), use of first name (14.1\%), scold (9.3\%), and hustle (9.2\%). However, the instruction related categories (pre-instruction, concurrent instruction, post instruction, questioning, physical assistance, positive modeling and negative modeling) accounted for the majority (53.8\% and a 2.27 R.P.M) of all the coded behaviours. A more detailed analysis of the instructional behaviours showed that the categories of pre-instruction (2.9\%), concurrent instruction (40.2\%) and post instruction (1.7\%) represent 44.8 percent of all recorded behaviours, totaling 1.89 R.P.M. It also means that questioning, physical assistance and modeling were strategies rarely used, with a total of $9 \%$ and 0.38 R.P.M.

The affective interaction related categories between coaches and players, praise, scold and hustle, accounted for $20.2 \%$ of the totality of the behaviours recorded, with a R.P.M of 0.86 . Of which scolding and hustle were both the more emphasized behaviours $(9.3 \%$ and $9.2 \%$ ), and followed by praise (1.7\%). The data revealed a ratio of 5.5: 1 between scolding and praise, respectively. The results also indicated that $14.1 \%$ of all independent behaviours were accompanied by the use of first name. Furthermore, management accounted for just 5.7 percent of total behaviours and uncodable with 6.2 per cent.

Table 2 provides an individual breakdown of the observed coaching behaviours for each coach who participated in the study. A number of similarities were emphasized, such as the high levels of instructional behaviours used. It also serves to highlight some interesting differences between coaches. In term of questioning and demonstration, only coaches B integrated such behaviours into her coaching practice, while the other three coaches employed these two behaviours to a far lesser extent. Coaches $\mathrm{A}$ and $\mathrm{B}$ also exhibited more hustle and scold behaviours than coaches C and D did.

\section{Table 1. Frequency, Percentage and Rate Per Minute (R.P.M) of Total Coaches' Behaviours as} Recorded by the ASUOI.

\begin{tabular}{llll}
\hline & Total & RPM & Percentage \\
Behaviour Categories & & & \\
& & & 14.1 \\
Use of first name & 429 & 0.6 & 2.9 \\
Pre-instruction & 88 & 0.12 & 40.2 \\
Concurrent instruction & 1225 & 1.7 & 1.7 \\
Post instruction & 52 & 0.07 & 2.5 \\
Questioning & 75 & 0.1 & 0.9 \\
Physical assistance & 26 & 0.04 & 4.5 \\
Positive modeling & 136 & 0.19 & 1.1 \\
Negative modeling & 35 & 0.05 & 9.2 \\
Hustle & 281 & 0.4 & 1.7 \\
Praise & 52 & 0.07 & 9.3 \\
Scold & 282 & 0.39 & 5.7 \\
Management & 173 & 0.24 & 6.2 \\
Uncodable & 190 & 0.26 & 100 \\
Total: & 3044 & 4.25 & \\
\hline
\end{tabular}


Table 2. The Behaviours Utilized by Coaches A, B, C and D as Recorded by the ASUOI

(Total Behaviours and \% of Behaviours in Parentheses).

\begin{tabular}{lllll}
\hline Behaviour Categories & Coach A & Coach B & Coach C & Coach D \\
Use of first name & $68(11.3)$ & $103(11.5)$ & $75(14.6)$ & $183(17.4)$ \\
Pre-instruction & $6(1)$ & $27(3)$ & $7(1.4)$ & $48(4.6)$ \\
Concurrent instruction & $214(35.7)$ & $321(36)$ & $249(48.5)$ & $441(41.8)$ \\
Post instruction & $5(0.8)$ & $26(2.9)$ & $9(1.8)$ & $12(1.1)$ \\
Questioning & $14(2.3)$ & $43(4.8)$ & $4(0.8)$ & $14(1.3)$ \\
Physical assistance & $8(1.3)$ & $8(0.9)$ & $5(1)$ & $5(0.5)$ \\
Positive modeling & $29(4.8)$ & $64(7.2)$ & $18(3.5)$ & $25(2.4)$ \\
Negative modeling & $14(2.4)$ & $17(1.9)$ & $3(0.6)$ & $1(0.1)$ \\
Hustle & $59(9.8)$ & $104(11.7)$ & $36(7)$ & $82(7.8)$ \\
Praise & $5(0.8)$ & $16(1.8)$ & $1(0.2)$ & $30(2.8)$ \\
Scold & $70(11.7)$ & $95(10.7)$ & $33(6.4)$ & $84(8)$ \\
Management & $31(5.2)$ & $47(5.3)$ & $38(7.4)$ & $57(5.4)$ \\
Uncodable & $77(12.8)$ & $21(2.4)$ & $35(6.8)$ & $57(5.4)$ \\
Total: & $600(100)$ & $892(100)$ & $513(100)$ & $1039(100)$ \\
\hline
\end{tabular}

Following the analysis of the interview transcripts and field notes, three themes related to the coaching practice of the participants emerged: authoritarian coaching style, active teaching and harsh and deterrent approach. These major categories were used to describe and understand coach behaviours of the participants.

\section{Authoritarian coaching}

The coaches exhibited directive behavior with authoritative image. They made all the decisions without any input of the players when coaching. Players had neither a say during the practice. The communication was one way but the instruction was clear with demonstration. Discipline was highly emphasized during the practice. Players were trained to follow orders and develop concentration. The coaches often used a loud voice to get attention of their players. They might act shocked and angry when players did not follow their directives. They were punitive and restrictive. The coaches always demanded attention and high expectation in players' performances. This command style and direct approach to instruction has its merit in the transmission of information especially in learning basic skills in basketball. Below are examples of the direct and controlling practices of coaching during the coaching sessions:
After the stretching, she briefly introduced and demonstrated the fast break drills and the players started the practice spontaneously...when Coach B found two players were chatting, she shouted and warned them to practice immediately... She seemed to control the players and made best use of every minute of the coaching practice (Coach B coaching field note 2)

...after the layup practice, Coach $D$ gathered the players and gave a short explanation and demonstration on the next practice. All players listened carefully and quickly spread out and started the next drill ... (Coach D coaching field note 1)

The coaches admitted that they adopted the authoritarian approach in their practice. They think this approach might help their control and enhance the performance of the players.

...the authoritarian approach was commonly used in my training. I will design several tasks for the players to follow and practice. Training targets were explicitly spelt out. The players will learn by reflecting and completing these tasks... there is a need to be authoritative and force the athletes to complete the tasks... (Coach A interview) 
... I usually adopt a stern and forceful approach in my coaching. I think this may help to develop the discipline of the players... without good discipline, it is hard to have good training outcome... (Coach B interview)

...I have high expectation and they call me Hell Coach. Indeed, I think this is authority. I admit that I am an authoritarian coach and the players need to accept this kind of coaching style... (Coach $D$ interview)

\section{Active teaching}

The coaches demonstrated their highly engagement of players in the training process. A coaching pattern emerged in which prolonged periods of dynamic and energetic instruction were stressed with verbal cues, short reminders, specific commands and corrections. Their practices were dominated with verbal behaviour pattern. On the sideline, all coaches issued comments and information to the players during the practice. They made clear expectations and set achievable goals for their players during the practice. Short reminding phases were commonly used, such as "head up", "watch your teammates", and "cut and support". Players were highly demanded for their input of efforts and practicing attitude. The coaches challenged the players to improve the quality of performances by adopting more hustle behaviours. This act helps to encourage physical effort from the players. They also constantly provided immediate feedback when they corrected the action of the players during their practicing. Supports were frequently provided in the coaching sessions.

-.I want my players get used of my voice and reminders. I understand my voice may act as some kind of pressure on them. If they get familiar to my comments, it will be helpful during the game play. Besides, I am sure my immediate feedback will help and improve their performances... (Coach D interview)

I try to prompt and remind the players. There is need to reinforce what the players should be doing. I want to remind before they have done it. Giving reminders would help to prevent their making mistakes... (Coach $C$ interview)
The coaches tried to personalize their interactions with the players by calling their names directly. The players would usually get attention after hearing their name. As Coach B commented, "this approach works and helps much. A player knows exactly who it is I am talking to. It gets somebody's attention when you use their name". The coaches also concerned about the performance of the players during the practice. Appropriate short interventions were used to help the learning of the players. They mostly stopped the practice and provided demonstrations and corrections for them if they discovered the players were not doing well.

...when one of the players did not shoot well, Coach $B$ stopped her and explained again. She tried to make the players execute correctly by following her way of shooting... (Coach B coaching field note 2)

...the coach were not satisfied with the performance of the players, he stopped the game several times and gave demonstrations for them. He further explained and provided a few offensive options for the players to choose... (Coach D field note 3)

\section{Harsh and deterrent}

All the coaches had created intense and demanding training environments for their players during coaching. They seemed to push their players to train hardly for every minute in the sessions and help them translate over into the game. Hustle behavours were widely used. They tried to develop players' athletic mentality and confidence. As Coach B stated, "encourage the players to push themselves and allow them to see they are capable of much more than they ever imagined, helps build a more confident player". Coach D also described, "every setting had a purpose, and they practice situations that were likely to occur in games. I expected hard and demanded of every player in their practice". They frequently scold the players and seldom praise their performances. Negative comments and criticism were commonly heard from the coaches within the coaching sessions. In some occasions, the coaches adopted exercise conditions as punishments when some players failed to demonstrate their expecting performance. It seems that these coaches thoughtfully employed discipline and punishment strategies to manage their players in coaching. Indeed, the coaches conceded that sarcasm and punishments were used to polish the skill learning of the players. 
...Coach A ordered those players who failed to score in each fast break practice to have ten push up. The players were shooting carefully during the fast break. Nevertheless, quite a number of players were doing push up at the sideline automatically. It seemed that they were used to this kind of punishment... (Coach A field note 3)

...I have considered using more praise instead of negative criticism. However, I want them to remember their incorrect practice and mistakes, severe criticism may serve this purpose. They will correct their practice immediately...I think praise without purpose is meaningless... (Coach A interview)

...if they are doing well, I will praise them. On the other hand, if they perform badly, I will scold them right away...If they have made mistakes, I will point them out and correct them immediately. Negative comments and criticisms were purposely used... (Coach $C$ interview)

\section{Coaching philosophical beliefs}

A sound coaching philosophy is the key to successful coaching practice. Coaching philosophies guide the behaviours and decisions of the coaches in coaching. Different coach has their own distinguish coach beliefs. Qualitative data generated from interview and field notes of coaching assist our understanding of the coaching philosophical beliefs of the participants in the study. The coaches asserted the importance of the development of players, the building of relationship with the players as well as the continuous personal development. They shared three common coaching philosophies in training basketball teams.

\section{Player development}

They focused on the learning of players and concerned their overall growth and developments. Besides basketball skills, they paid attention to the academic and personal development of the players. All coaches emphasized the development of both the basic skills and tactics in their coaching sessions. They regard both the fundamental techniques and group tactics are equally important in preparing the players to take part in the competition. The allocation of the training of basics or tactics depends on the progression of the players as well as the period of the season. They believed the players need to learn from the basics and develop progressively. From the observation in coaching practices, two coaches concentrated more on basic fundamental and individual skills in the coaching practices, while the other two designed more tactical drills and the application of basic techniques in their practice sessions.

...my training plans are a little different in preseason, in-season and competition period. I will concentrate more on physical conditioning and basic skills during pre-season. Tactics will be introduced at the start of in-season... (Coach $C$ interview)

...the whole team will concentrate on developing physical fitness and the basic of defense. We will also take part in some basketball competitions. The main purpose is to maintain their practice in basketball during this period.... (Coach A interview)

Moreover, the coaches shared some common coaching strategies in training. Maintaining the players' interest in basketball and setting goals in the training tasks will help the players develop as well as getting succeeded. Create a fun learning climate is important in attracting and maintaining players to stay in training. Setting small measurable and attainable goals will help the players see their own improvements and success.

...we need to make the players feel confident to accomplish the tasks... the activities need to be fun and they all show interest...for your team to be successful you must combine fun and enjoyment with an atmosphere that makes player want to learn (Coach $B$ interview)

..If they do not like basketball, how can you enhance their performance? For younger players, I would introduce more fun activities...setting achievable targets and goals is also important... (Coach $D$ interview)

The coaches stressed that addressing the needs of their players was the basic principle of their coaching philosophy. Coach A stressed the importance of developing the basic skills, while Coach B focused the training based on the characteristics of the players as well as their opponents. Coach $\mathrm{C}$ and D would take the quality and skill levels of the players into consideration when designing the training activities. All coaches specially cared about the learning of the players. They aim at developing the players into independent learners. They 
expect to see the players can solve their own problems and are able to read the game during the game play situations. Able to make appropriate decision and execute proper skills in game situations are the common training targets of the players.

...I want to let them go through the processes of making decisions and choices during the game play. I do not want them to rely on me telling them what to do and when to do in the game. I usually design small size games in the training and let the players get used to apply their learnt skills and tactics in the game situation... (Coach B Interview)

...my train is to improve their skill level and their understanding of the game...help them identify situations in game where they can improve and develop... (Coach $C$ interview)

All players are secondary school students and need to finish assignments in different academic subjects at school. Improper allocation of time in sport training and academic studies might influence their taking part in the school sports. Secondary education in Hong Kong is highly academic demanding; players might face pressure and high expectations from parents and school teachers. The coaches in the study concerned and cared about the academic and personal development of their players. They considered and tried to help the players maintain the balance of academic studies and basketball development during coaching. Their coaching philosophies included more than winning games. It involved all round development who would be successful in life. They teach their players about life through sport.

...outside the basketball court, I always cared about them and lead them to have a proper life in future...I need to consider their studies...when I am coaching, I have to consider whether the players will have tests and examination the next day. Do they have sufficient time in preparing the tests and examinations... (Coach $B$ interview)

...not only in basketball, I also concerned their personal growth and how they develop in future... basketball is a means, not an end. I focused on the development of my players...I teach my players how to react to referee, how to control their characters and emotions. I believe these will serve them well in life... (Coach A interview) ...some of my players might violate school regulations such as using foul languages and fighting, I also acted as counselor and helped them to correct and improve these behavioral problems... to provide not only basketball skill advice, but to shape them into respectable human beings... (Coach $D$ interview)

\section{Building relationships}

All coaches agreed that creating a positive relationship with their players is the prerequisite of successful coaching. Having good relationship with the players will help them to achieve several training goals in coaching, such as improve performance, maintain fitness and enjoy participation in training. Indeed, establishing coach-athlete relationship also enhances mutual respect and trust between players and coach. It seems that the coaches in the present study had made much effort in building positive relationship with the players. They mentioned that non-sport communication helped to shorten the distance with the players. They usually made use of the non-coaching situations and communicate with the players and the players liked to talk about the topic outside basketball. Free and regular communication helps the understanding between the coaches and the players.

...if you bring something up outside basketball, the players show more interest, it is especially true beyond the coaching sessions. They seems to like this kind two-way communication ... (Coach A interview)

...talking a lot, but not just talking about basketball and your coaching but something taking it further than...can build up a better relationship... (Coach D interview)

While coach $\mathrm{B}$ and $\mathrm{C}$ pointed out giving one-to-one feedback in training can build up relationship. The coachathlete relationship requires frequent feedback and support. When the players feel the coaches care and support their learning, they may trust and pay respect to the coaches in return. Indeed, the coaches in the study concerned and showed interest in their players within the coaching process. Demonstrate interest in players is the crucial factor that helps establish trust and respect between coaches and athletes. The coaches spent much time and effort to observe and understand their players. As Coach 
C explained, "I invested time, energy and effort into my players. I have to study and analyze and find out how you can help them". The relationship between coaches and players is strengthened when coaches provide care and support to their players.

...I think you earn their respect by showing interest in them...showing that your are there to improve them... if the coaches do not care about their players, then the players will not learn to trust and respect the coach in return... (Coach $D$ interview)

...building relationship is important...make them have a good feeling...like a family and training with brothers together... (Coach $\mathrm{C}$ interview)

The coaches admitted that establishing trust and positive relationship help the players accept the authoritarian and harsh coaching style. After gaining trust, the players would also admit negative comments, criticisms and punishments from the coaches. The players might understand these all means adopted were for their improvements in training.

...if you cannot have that kind of connection, it is hard for them to trust my training style...some of the players will leave after few coaching session (Coach A interview)

...no matter how I criticize and punish them, they trust that all are for their own good...in some occasions, I will praise and comfort them to help gaining self-esteem... (Coach D interview)

\section{Continuous personal development}

The coaches showed great desire to learn and improve their coaching practice. One of the common coaching philosophies shared by the coaches is personal development and commitment to learning. They recognize coaching process is demanding and they need to continuously update coaching knowledge in acquiring the tendency and techniques of basketball to cater the broad range of needs from the players. They highlighted the importance of reflective practice and used to evaluate their coaching performance after coaching sessions. They treasured their own coaching experience and tried to make sense from them. They made use of the experience by practicing and reflecting. They said that they learnt much from their coaching experiences. They understand their development as a continuous process undertaken with an express will to improve. Coach $\mathrm{C}$ noted that "assessing coaching performance after a training session is important and also regarded as part of the learning process" and he would re-think the ways he trained the players and see whether to have some better ways in future training.

...I self-evaluated a lot when I coached, I find some methods are good but some don't work. I also re-watch the videos of my coaching during game play and reflect my decision making at that time...I learnt from my own mistakes... (Coach D interview)

.I jot notes for my coaching and I used to reflect my practices based on these records...I also asked the players' opinions about my coaching...the process help me to self-aware the effectiveness of my coaching. (Coach A interview)

Moreover, the participants' desire to excel and strive for excellence made them committed about basketball coaching. They usually update coaching knowledge through reading and observation. They acquired basketball knowledge through books and Internet. They tended to consult books and search Websites for training drills and related coaching topics such as sport psychology, physical conditioning and nutrition.

...I have read books and made use of the computer to search related websites. I find them very useful. I always come up with new training skills and drills... (Coach D interview)

...there are so many ways you can help your players. I need to train their mentality, their fitness level...I have seen some books out there with advance coaching topics... (Coach A Interview)

The coaches also refreshed their knowledge by watching basketball competitions and the practices of other coaches. Coach B affirmed that the values of watching competitions that help to understand the trends of tactics employed and reassess the needs of changing the focus in coaching tactics and techniques. While coaches $\mathrm{C}$ and $\mathrm{D}$ confessed that they used to learn coaching by observing the practices of others. Observing the practices of other coaches might give them insights and new ideas in coaching. 
... like to observe the practices of some of my colleagues and friends...I usually learn some new ideas and information from their practices... (Coach $C$ interview)

Every coach has his or her own style and emphasis, watching more coaches' practice will see their philosophies...this is one of the ways to broaden my coaching knowledge... (Coach D interview)

\section{Discussion}

Results of the present study have shown the common coaching practice and coaching philosophies of the participants in coaching basketball. Consistent with previous observational research on successful coaches, instruction was found to be the most frequently utilized coaching behaviours (53.8\%) by the coaches under study. The coaches also spent a great part of the practice using instructional behaviours (pre-instruction, concurrent instruction and the post instruction)(44.8\%). These profiles are also found in other coaches investigations (Becker \& Wrisberg, 2008; Claxton, 1988; Cushion \& Jones, 2001; Horton, Baker, \& Deakin, 2005; Lacy \& Goldston, 1990; Lacy \& Martin, 1994; Potrac et al., 2002; Potrac et al., 2007; Rupert \& Buschner, 1989). It seems that instruction is the most significant aspect of the coach's role (Tinning, 1982). When studying the coaching practice of the legend basketball coach John Wooden, it was found 75\% of his act of teaching carried some pedagogic information. Being a teacher is one of the defining roles of a coach and helping the athletes learn (Hodges \& Franks, 2002). Other researchers used role theory to explain the instructional behaviours exhibited by the coaches (Jones, Armour, \& Potrac, 2002, 2004). The previous socialization and experiences of coaches influenced their beliefs of adopting instruction as appropriate and effective coaching behaviours. Besides, the practices of other successful coaches with high level of instructions would make them to perceive it to be the most effective approach to fulfill the requirements of the coaching role as well (Bloom, Crumpton, \& Anderson, 1999; Potrac, Jones, \& Armour, 2002). The high level instructional behaviours observed in this study could also represent an effort by the coaches to prove their knowledge and expertise in basketball as well as the power relationship exists between coach and athlete (Potrac, Jones, \& Cushion, 2007). Coakley (2009) suggested high levels of instruction would control as many variables as possible within the coaching process and emphasized the outcome-focused performance. It is possible that the coaches in the study used high percentages of instructional strategies and emphasized the performance outcome of the players.

The percentage of the behaviours of pre-instruction and post instruction for the totality of coaches was $2.9 \%$ and $1.7 \%$ respectively, less than previous studies in coaches behaviours (Cushion \& Jones, 2001; Lacy \& Goldston,1990; Lacy \& Martin, 1994; Potrac, Jones, \& Armour, 2002; Potrac, Jones, \& Cushion, 2007; Rupert \& Buschner, 1989). As pre-instruction precedes the practice, the information provided depends on the nature and purpose of the training. In the present study, the coaches seemed to give brief explanation with demonstration for the introducing of the activities in order to save time for practicing. They also employed short interventions for the re-correction of the players. As the training time for school basketball teams in Hong Kong was limited, the coaches usually allocated most time for the players to practice the techniques and tactics (Williams \& Hodges, 2005).

Concerning the use of concurrent instruction behaviour, it accounted for $40.2 \%$ of the total coaching behaviours in the present study. This is recognition of the importance of concurrent instruction, the supporting behaviour with attendance of the players' activities with instruction provided during the execution. Giving learning cues and immediate feedback will support players to learn and is essential to effective coaching (Horn, 2008; Solomon et al., 1996). Short reminders related to specific task performance were frequently heard during the practicing of the players. In this case, the instruction was considerable and highly task specific.

The present study demonstrates $14.1 \%$ of behaviours accompanied by the first name which shared similar results with other studies (Cushion \& Jones, 2001; Lacy \& Darst, 1985; Lacy \& Martin, 1994; Potrac, Jones, \& Armour, 2002; Potrac, Jones, \& Cushion, 2007). Cushion and Jones (2001) demonstrated that the use of first name might be related to the type of practice and purpose of feedback given. They verified that the coaches of the premiership when addressing specific mistakes to the "team" practices and used the first name more than the National wide Leagues coaches who applied more "group" practices, when transmitting information to the players 
often containing generic mistakes affecting all players. Moreover, the use of first name can be regarded as special strategy that the coaches in the study employed to help players learn in practicing. Studies showed that the individuals have limited ability to store and use information in short term memory (Magill, 2001). The use of the first name in instruction may attract players' attention and increase the level of players' information retention.

'Scolding' was found to be a frequently used behaviour and 'praise' was a seldom used behaviour by the coaches in the present study. The results contradict with the previous literature in suggesting that successful and effective coaches favoured the use of praise in relation to scolding in coaching (Claxton, 1988; Cushion \& Jones, 2001; Lacy \& Darst, 1985; Lacy \& Goldston, 1990; Lacy \& Martin, 1994; Potrac, Jones, \& Armour, 2002; Potrac, Jones, \& Cushion, 2007; Rupert \& Buschner, 1989; Tharp \& Gallimore; 1976). As Tharp and Gallimore (1976) pointed out that players with strong motivation oriented in specific goals may make the coach think it is unnecessary to make use of praise. Besides, a possible explanation of this could lie in the personal coaching philosophy of the coaches observed. The coaches in the present study wanted to control the coaching environment and process and adopted the authoritarian style in coaching, it is possible that they may utilize more scolding behaviours when instructing. Potrac, Jones, and Cushion (2007) commented that scold behaviours could be regarded as 'coercive power' (French \& Raven, 1959) and dysfunctional as it alienates people and build up resentment. The overuse of scold behaviour might result in a perceived loss of respect for the coach in the eyes of the players and a decline in the receptiveness of the players to the coach's instruction and advice. It eventually damaged the coachplayer relationship. Researchers indicated that coaches were often unaware of the behaviours exhibited toward athletes in practice (DeMarco, Mancini, \& West, 1997; Krane, Eklund, \& McDermott, 1991). The coaches in the study might not aware their overuse and the negative influence of scold behaviours.

The analysis of the coach behaviours in the present study demonstrated that hustle was the fourth behaviour with the larger use during the coaching with the percentile values of $9.2 \%$. This implies the coaches try to bring the degree of high intensity to the practice setting. Throughout the coaching, the coaches reinforce the importance of intensity by directing hustle statements toward individual players more than toward the team as a whole. The main purpose of using hustle is to encourage the players to a better performance and effort (Lacy \& Darst, 1985). Providing great amount of hustle feedback may serve to increase the overall intensity of the coaching practices and promote a more game-like atmosphere. It is likely that the coaches attempt to create a training environment for the players to practice like they play in games.

The coaching practices in the present study more closely linked to traditional Eastern leadership culture. The coaches seem to demonstrate a paternalistic leadership style with characteristics unique to Chinese culture. Hsu, Huang, Chih, and Dong (2005) defined paternalistic leadership style as a leadership method that comprises strict discipline and authority, paternal kindness, and moral integrity within a ruling atmosphere. Farh and Cheng (2000) suggested that paternalistic leadership is comprised of three leadership styles: benevolent leadership, authoritarian leadership, and virtuous leadership. Benevolent leadership is characterized by engagement in individual, comprehensive, and long-term care for the welfare of subordinates. Authoritarian leadership is characterized by absolute authority that cannot be challenged. Virtuous leadership is characterized by exceptional personal conduct and selfcultivation as to gain subordinates' respect and esteem. These leadership behaviours were strongly reflected by the coaches during their coaching practices. They attempted to control the coaching process and training environment but cared for the development of the players. The coaches seemed to act in the role of parent or teacher during team training and enabling the learners to develop as players. They always provided advice and encouragement after coaching. It seemed that both the virtuous and benevolent leadership styles of the coaches were sensed by the players and the authoritarian behaviours exhibited by the coaches were understood as a learning tool. Nevertheless, it is advantageous for the basketball coaches in the study not to engage in authoritarian leadership and, instead, to behave in a virtuous and benevolent leadership role in order to create a harmonious training atmosphere and foster trust and security among the team players.

The traditional culture in Chinese society indeed permits and reinforces the coaches in the study adopting the authoritative behaviours during coaching. Cardinal relationships in Chinese society, such as sovereign 
and minister and father and son, form the basis of an authoritative value system ( $\mathrm{Si}$, Duan, Li \& Jiang, 2011). The principle of respecting the superior within the dyad specifies the social exchange and interaction among Chinese people (Hwang \& Han, 2010). Due to traditional values, sports coach may play the commanding role with their athletes and affirm distinct values of authoritativeness, morality and consideration (Yang, 2004). The players in the study may respect and obey their sport coach and accept their authoritative coaching behaviours. The relationship between the coach and players can be described as intimate and authoritative, requiring players to obey and respect various behavioural boundaries. However, this dyadic authoritative relationship may be challenged and prone to change when the players mature and experience new knowledge.

\section{Conclusion}

It must be cautioned that the results of the study cannot be generalized beyond this group of coaches and players. Additional studies in coaching practices and philosophy of a greater number of high performance coaches would provide further insight in coaching basketball. However, the findings of the present study have shed increasing light on how successful secondary school basketball coaches coach in the practice environment. The current results suggest high level of instructional behaviours during coaching, the use of first name, authoritative and deterrent approach, maintaining good relationship, caring the development of players and continuous self development are essential coaching practices and philosophies adopted by the successful basketball coaches in the study. These findings showed good pedagogical practices that promote active learning and meaningful affective relationships in coaching. The findings can also have a valuable contribution to coach education, particularly in school sport training. Although this study enhanced the understanding of the coaching philosophy of high performance secondary school basketball coaches and how they practice during coaching, some limitations need to be addressed. First, the investigations focused solely on the coaches' practice and philosophies. Players' viewpoints were not examined and considered. Future studies should include the understanding of the players' experiences of being coached and provide a more complete picture of the coaching process. Second, results might be specific only to four basketball coaches and their players being observed and studied. It might be interesting for future research to compare the current results with high performance primary school basketball coaches or secondary school coaches in other sports events. Trying to determine whether there are common coaching practices and philosophies.

The current study is an initial step studying the coaching philosophies and practices of high performance secondary school coaches in Hong Kong. Although this study provides insight into the coaching philosophy of high performance basketball coaches and how they practice in coaching, it cannot be concluded that basketball coaches who do not possess these coaching behaviors and philosophies will be unsuccessful. Since there is no single designated style of coaching that is deemed to be the only successful coaching style, the most important rule is to understand their players and coach according to their needs.

\section{References}

Becker, A. J., \& Wrisberg, C. A. (2008). Effective coaching in action: Observations of legendary collegiate basketball coach Pat Summitt. The Sport Psychologist, 22(2), 197-211.

Bloom, G. A., Crumpton, R., \& Anderson, J. E. (1999). A systematic observation study of the teaching behaviours of expert basketball coach. The Sport Psychologist, 13(2), 157-170.

Bloom, G. A., \& Salmela, J. H. (2000). Personal characteristics of expert team sport coaches. Journal of Sport Pedagogy, 6(2), 56-76.

Bogdan, R. C., \& Biklen, S. K. (1992). Qualitative research for education: An introduction to theory and methods. Boston: Allyn \& Bacon.

Brewer, C. J., \& Jones, R. L. (2002). A Five-stage process for establishing contextually valid systematic observation instruments: The case of rugby union. The Sport Psychologist 16( 2), 139-61.

Claxton, B. D. (1988). A systematic observation of more and less successful high school tennis coaches. Journal of Teaching in Physical Education, 7(4), 302-310. 
Claxton, B. D., \& Lacy, A. C. (1986). A comparison of practice field behaviors between winning high school football and tennis coaches. Journal of Applied Research in Coaching and Athletics, 1(3), 188-200.

Coakley, J. J. (2009). Sport in society: Issues and Controversies (10th ed.). New York: McGraw-Hill.

Coté, J. (1998). Coaching, research and intervention: An introduction to the special issue, AVANTE, 4(3), 1-15.

Coté, J., \& Salmela, J. H. (1996). The organizational tasks of high performance gymnastic coaches. The Sport Psychologist, 10(3), 247-260.

Coté, J., Salmela, J. H., \& Russell, S. J. (1995). The knowledge of high performance gymnastic coaches: Competition and training considerations. The Sport Psychologist, 9(1), 76-95.

Coté, J., Salmela, J. H., Trudel, P., Baria, A., \& Russell, S. J. (1995). The coaching model: A grounded assessment of expert gymnastic coaches' knowledge. Journal of Sport \& Exercise Psychology, 17(1), 1-17.

Coté, J., \& Sedgwick, W. (2003). Effective behaviours of expert rowing coaches: A qualitative investigation of Canadian athletes and coaches. International Sports Journal, 7(1), 62-77.

Cushion, C. J., \& Jones, R. L. (2001). A systematic observation of professional top-level youth soccer coaches. Journal of Sport Behaviour, 24(4), 354-378.

DeMarco,G. M. P., Mancini,V. H., \& Wuest, D. A. (1997). Reflections on change: A qualitative and quantitative analysis of a baseball coaches' behavior. Journal of Sport Behavior, 20(2), $135-163$.

Denzin, N. K. (1989). The research act - A theoretical introduction to sociological methods (3rd ed.). Englewood Cliffs, NJ: Prentice-Hall.

Denzin, N. K., \& Lincoln, Y.S. (Eds.). (1994). Handbook of qualitative research. Thousand Oaks, CA: Sage Publications.
Douge, B., \& Hastie, P. (1993). Coach effectiveness. Sport Science Review, 2(2), 14-29.

Duffy, P., Hartley, H., Bales, J., Crespo, M., Dick, F., Vardhan, D., Nordmann, L., \& Curado, J. (2011). Sport coach as a 'profession': Challenges and future directions. International Journal of Coaching Science, 5(2), 93-123.

Erickson, K (2009). State space grids: First application of a novel methodology to examine coach-athlete interactions in competitive youth sport. Ontario: Queen's University Kingston.

Farh, J. L., \& Cheng, B. S. (2000). A cultural analysis of paternalistic leadership in Chinese organizations [In Chinese]. Indigenous Psychological Research in Chinese Societies, 13, 127-180.

French, J. R. P., \& Raven, B. (1959). The bases of social power. In D. Cartwright (Ed), Studies in social power (pp. 259-269). Ann Arbor: University of Michigan Press.

Gallimore, R., \& Tharpe, R. (2004). What a coach can teach a teacher, 1975-2004: Reflections and reanalysis of John Wooden's teaching practices. The Sport Psychologist, 18(2), 119 - 137.

Hardin, B. (2000). Coaching expertise in high school athletics: Characteristics of expert high school coaches. Applied Research in Coaching and Athletics Annual, 15, 24-38.

Hardin, B., \& Bennett, G. (2002). The instructional attributes of a successful college baseball coach. Applied Research in Coaching and Athletics Annual, 17, 43-62.

Hodges, N. J., \& Franks, I. M. (2002). Modelling coaching practice: The role of instruction and demonstration. Journal of Sports Sciences, 20(10), 793-811.

Horn, T. S. (2008). Coaching effectiveness in the sport domain. In T.S. Horn (Ed.), Advances in sport psychology (pp. 239-268). Champaign, IL: Human Kinetics. 
Horton, S., Baker, J., \& Deakin, J. (2005). Experts in action: A systematic observation of 5 national team coaches. International Journal of Sport Psychology, 36(4), 299-319.

Hsu, H. M., Huang, Y. W., Chih, S. H., \& Dong, J. L. (2005). An award-winning benefit study to the specific competitive teams of mainland China from 27 and 28 Olympic Games [In Chinese]. Nanya Institute of Technology, 25, 239-254.

Hwang, K. K., \& Han, K. H. (2010). Face and morality in Confucian society. In M. H. Bond (Ed.), The Oxford handbook of Chinese psychology (pp. 479498). Oxford: Oxford University Press.

Jones, R., Armour, K., \& Potrac, P. (2002). Understanding the coaching process: A framework for social analysis. Quest, 54(1), 34-48.

Jones, R., Armour, K., \& Potrac, P. (2004). Sports coaching cultures: From practice to theory. London: Routledge.

Jones, D. F., Housner, L. D., \& Kornspan, A. S. (1995). A comparative analysis of expert and novice basketball coaches' practice planning. Applied Research in Coaching and Athletics Annual, 10, 201227

Kahan, D. (1999). Coaching behaviour: A review of the systematic observation literature. Applied Research in Coaching and Athletics Annual, 14, 17-58.

Krane, V., Eklund, R., \& McDermott, M. (1991). Collaborative action research and behavioral coaching intervention: A case study. Applied Research in Coaching and Athletics Annual, 6, 119-148.

Lacy, A. C., \& Darst, P. W. (1984). Evolution of a systematic observation instrument: The A.S.U. Observation instrument. Journal of Teaching in Physical Education, 3(3), 59-66.

Lacy, A. C., \& Darst, P. W. (1985). Systematic observation of behaviours of winning high school head football coaches. Journal of Teaching in Physical Education, 4(4), 256-270.
Lacy, A. C., \& Darst, P. W. (1989). The Arizona State University Observation Instrument (ASUOI). In P. W. Darst, D. B. Zakrajsek \& V. H. Mancini (Eds.), Analyzing physical education and sport instruction (2nd ed., pp. 369-378). Champaign, IL: Human Kinetics.

Lacy, A. C., \& Goldston, P. D. (1990). Behaviour analysis of male and female coaches in high school girls' basketball. Journal of Sport Beahviour, 13(1), 29-39.

Lacy, A. C, \& Martin, D. L (1994). Analysis of starter/ non-starter motor-skill engagement and coaching behaviours in collegiate women's volleyball. Journal of Teaching in Physical Education, 13(1), 95-107.

LeCompte, M. D., \& Preissle, J. (1993) Ethnography and qualitative design in educational research. San Diego, CA: Academic Press.

Lincoln, Y., \& Guba, E. (1985). Naturalistic inquiry. Beverly Hills, CA: Sage.

Magill, R. (2001). Augmented feedback in motor skill acquisition. In R N. Singer, H. A. Hausenblas \& C. M. Janelle (Eds.), Handbook of sport psychology (pp. 86-114). New York: Wiley.

Manning, P. K. (1991) Analytic induction. In K. Plummer (Ed.), Symbolic interactionism: Contemporary issues, Vol. 2 (pp. 301-430). Brookfield, VT: Edward Elgar.

Marshall, C., \& Rossman, G. B. (1995). Designing qualitative research ( $2 \mathrm{nd}$ ed.). Thousand Oaks, CA: Sage Publication.

Martens, R. (1987). Science, knowledge and sport psychology. The Sports Psychologist, 1(1), 29 - 55.

Merriam, S. B. (1998). Qualitative research and case study applications in education. San Francisco, CA: Jossey-Bass Inc.

Mesquita, I., Sobrinho, A., Rosado, A., Pereira, F., \& Milistetd, M. (2008). A systematic observation of youth amateur volleyball coaches behaviours. International Journal of Applied Sports Sciences, 20(2), 37-58. 
Miller, A. W. (1992). Systematic observation of behavior similarities of various youth sport soccer coaches. Physical Educator, 49(3), 136 - 143.

Moraes, L. C., \& Salmela, J. H. (2001). Influences of the Canadian context on beliefs of expert Canadian, Japanese and European judo coaches. In M. Pirritano \& A. Cei (Eds.), Psicologia dello sport (Psychology of sport) (pp. 61-74). CONI (School of Sport): Rome.

More, K. G., \& Franks, I. M. (1996). Analysis and modification of verbal coaching behaviors. The usefulness of data driven interventions strategy. Journal of Sport Sciences, 14(6), 523-543.

Patton, M. Q. (1990). Qualitative evaluation and research methods (2nd ed.). Beverly Hill, CA: Sage.

Potrac, P., Brewer, C., Jones, R. L., Armour, K., \& Hoff, J. (2000). Toward an holistic understanding of the coaching process. Quest, 52(2), 186 - 199.

Potrac, P., \& Jones, R. L. (1999). The invisible ingredient in coaching knowledge: A case for recognising and researching the social component. Sociology of Sport Online, 2(1) (available at: 5http://physed.otago.ac.nz/ sosol/v2il/v2ila5.htm4).

Potrac, P., Jones, R. L., \& Armour, K. (2002). It's all about getting respect: The coaching behaviours of an expert English soccer coach. Sport, Education and Society, 7(2), 183-202.

Potrac, P., Jones, R. L., \& Cushion, C. (2007). Understanding power and the coach's role in professional English soccer: A preliminary investigation of coach behaviour. Soccer and Society, 8(1), 33-49.

Rupert, T., \& Buschner, C. (1989). Teaching and coaching: A comparison of instructional behaviors. Journal of Teaching in Physical Education, 9(1), 49-57.

Rushall, B. S. (1977). Two observational schedules for sporting and physical education environments. Canadian Journal of Applied Sports Sciences, 2(1), $15-21$.
Segrave, J., \& Ciancio, C. A. (1990). An observational study of a successful Pop Warner football coach. Journal of Teaching in Physical Education, 9(4), 294 - 306.

Si, G., Duan, Y., Li, H.Y., \& Jiang, X. (2011). An exploration into social-cultural meridians of Chinese athletes' psychological training. Journal of Clinical Sport Psychology, 5(4), 325-338.

Smith, R. E., Smoll, F. L., \& Hunt, E. B. (1977). A system for the behavioral assessment of athletic coaches. Research Quarterly, 48(4), 401-406.

Soloman, G. B., Striegel, D. A., Eliot, J. F., Heon, S. N., \& Maas, J. L. (1996). The self fulfilling prophecy in college basketball: Implications for effective coaching. Journal of Applied Sport Psychology, 8(1), 44-59.

Sports Development Board. (2003). Sports participation survey 2001. Hong Kong: Sports Development Board.

Tharp, R. G., \& Gallimore, R. (1976). What a coach can teach a teacher. Psychology Today, 9(1), 75-78.

Thomas, J. R., Nelson, J. K., Silverman, S. J. \& (2011). Research methods in physical activity (6th ed.). Champaign, IL: Human Kinetics.

Tinning, R. I. (1982). Teacher reaction to the trial materials: A Victorian case study. Australian Journal for Health: Physical Education \& Recreation, 95, 1114.

Trudel, P., Coté, J., \& Donohue, J. (1993). Direct observations of coaches' behaviours during training and competition: A literature review. In S. Serpa, J. Alves, V. Ferreira, \& A. Paulo-Brito (Eds.), Proceedings of the VIII world congress of sport psychology (pp. 316 - 319). Lisbon: FMH.

Van der Mars, H. (1989). Observer reliability: Issues and procedure. In P. W. Darst, D. B. Zakrajsek \& V. H. Mancini (Eds.), Analyzing physical education and sport instruction (2nd ed., pp. 53-80). Champaign, IL: Human Kinetics. 
Van der Mars, H., Darst, P. W., \& Sariscany, M. J. (1991). Practice behaviours of elite archers and their coaches. Journal of Sport Behavior, 14(2), 103 - 112.

Wang, J., \& Straub, W. F. (2012). An investigation into the coaching approach of a successful world class soccer coach: Anson Dorrance. International Journal of Sport Science \& Coaching, 7(3), 431-447.

Williams, A. M., \& Hodges, N. J. (2005). Practice, instruction and skill acquisition: Challenging tradition. Journal of Sports Sciences, 23(6), 637-650.

Yang, G. S. (2004). Chinese psychology and behavior: Indigenous research. Beijing: China Renmin University Press. (in Chinese)

Zeng, H. Z., Leung, R. W., Bian., W., \& Liu, W. (2009). The differences in coaching behaviors between individual and team sports at college varsity level. Asian Journal of Physical Education \& Recreation, 15(2), 35-42.

\section{Correspondence:}

Dr. Alberto CRUZ

Department of Health \& Physical Education The Hong Kong Institute of Education 10 Lo Ping Road, Tai Po, New Territories, Hong Kong

高達倫博士

香港教育學院健康與體育學系

香港新界大埔露屏路十號

Telephone:(852) 29487847

Fax: (852) 29487848

E-mail: acruz@ied.edu.hk

\section{Appendix 1. Behavior categories and definitions of the AUSOI}

\begin{tabular}{|c|c|}
\hline Behavior & Definitions \\
\hline Use of the first name & Using the first name or nickname when speaking directly to a player. \\
\hline Pre-instruction & $\begin{array}{l}\text { Initial information given to player(s) preceding the desired action to be } \\
\text { executed. It explains how to execute a skill, play, strategy and so forth } \\
\text { associated with the sport. }\end{array}$ \\
\hline Concurrent instruction & Cues or reminders given during the actual execution of the skill or play. \\
\hline Post instruction & $\begin{array}{l}\text { Correction, re-explanation, or instructional feedback given after the execution } \\
\text { of the skill or play. }\end{array}$ \\
\hline Questioning & $\begin{array}{l}\text { Any question to player(s) concerning strategies, techniques, assignments, and } \\
\text { so forth associated with the sport. }\end{array}$ \\
\hline Physical assistance & $\begin{array}{l}\text { Physically moving the player's body to the proper position or through the } \\
\text { correct range of a motion of a skill. }\end{array}$ \\
\hline Positive modeling & A demonstration of the correct performance of a skill or playing technique. \\
\hline Negative modeling & $\begin{array}{l}\text { A demonstration of the incorrect performance of a skill or playing } \\
\text { technique. }\end{array}$ \\
\hline Hustle & Verbal statements intended to intensify the efforts of the player(s) \\
\hline Praise & Verbal or non-verbal compliments, statements, or signs of acceptance. \\
\hline Scold & Verbal or non-verbal behaviours of displeasure. \\
\hline Management & $\begin{array}{l}\text { Verbal or non-verbal behaviours related to the organizational details of } \\
\text { practice sessions not referring to strategies or fundamentals of the sport. }\end{array}$ \\
\hline Uncodable & $\begin{array}{l}\text { Any behaviour that cannot be seen or heard, or does not fit into the } \\
\text { above categories. }\end{array}$ \\
\hline $\begin{array}{l}\text { Silence (Used only with interval } \\
\text { recording) }\end{array}$ & $\begin{array}{l}\text { Period of time when the coach is not talking, when listening to a player, } \\
\text { or monitoring activities. }\end{array}$ \\
\hline
\end{tabular}

Definitions from Evolution of systematic observation instrument: The A.S.U. Observation instrument. Lacy, A. C., \& Darst, P. W. (1984). Journal of Teaching in Physical Education, 3(3), 59-66. 